\author{
Thomas LUGER ${ }^{1}$ \\ Linda DE RAEVE ${ }^{2}$ \\ Carlo GELMETTI ${ }^{3}$ \\ Talia KAKOUROU ${ }^{4}$ \\ Alexandra KATSAROU ${ }^{5}$ \\ Julien LAMBERT ${ }^{6}$ \\ Marie-Anne MORREN ${ }^{7}$ \\ Arnold ORANJE ${ }^{8}$ \\ Mireille RUER ${ }^{9}$ \\ Server SERDAROGLU ${ }^{10}$ \\ Antonio TORRELO ${ }^{11}$ \\ Thomas WERFEL ${ }^{12}$
}

${ }^{1}$ Department of Dermatology, University of Münster, von-Esmarch-Str. 58, 48149

Münster, Germany

${ }^{2}$ Department of Dermatology, UZ Brussel,

Vrije Universiteit Brussel, Laarbeeklaan

101, 1090 Brussels, Belgium

${ }^{3}$ Department of Pathophysiology and

Transplantation, University of Milan,

Ospedale Maggiore Policlinico, Clinica

Dermatologica Via Pace, 9 - 20122 Milan,

Italy

${ }^{4}$ First Department of Pediatrics, University of Athens, Aghia Sophia Children's

Hospital, 11527 Athens, Greece

${ }^{5}$ Department of Dermatology, University of Athens, A. Syggros Hospital, Dragoumi 5,

16121 Athens, Greece

${ }^{6}$ Department of Dermatology, University

Hospital of Antwerp, University of

Antwerp, Wilrijkstraat 10, 2650 Edegem,

Belgium

${ }^{7}$ Department of Dermatology, Universitaire Ziekenhuizen Leuven and Catholic

University of Leuven, Kapucijnenvoer 33,

B-3000 Leuven, Belgium

${ }^{8}$ Department of Pediatrics, Division of

Pediatric Dermatology, Erasmus MC -

Sophia Children's Hospital, dr.

Molewaterplein 60, 3015 GJ, Rotterdam, the

Netherlands

${ }^{9}$ Medical center Le Bâteau-Blanc, Chemin de Paradis, 13500 Martigues, France

${ }^{10}$ Department of Dermatology, Cerrahpasa

Medical Faculty, University of Istanbul,

Fatih, 34098, Istanbul, Turkey

${ }^{11}$ Department of Dermatology, Hospital

Niño Jesus, Avenida Menendez Pelayo 65,

28009-Madrid, Spain

${ }^{12}$ Department of Dermatology and Allergy,

Hannover Medical School, OE 6600,

Carl-Neuberg-Str. 1, D 30625 Hannover,

Germany

Reprints: T. Luger

<luger@uni-muenster.de>

Article accepted on 6/30/2013

\section{Recommendations for pimecrolimus $1 \%$ cream in the treatment of mild-to-moderate atopic dermatitis: from medical needs to a new treatment algorithm}

Pimecrolimus $1 \%$ cream is an effective, non-corticosteroid, topical antiinflammatory treatment for atopic dermatitis (AD). The aim of this article was to review published clinical data that have examined how pimecrolimus can address the medical needs of AD patients. Clinical studies have demonstrated that early treatment with pimecrolimus decreases the progression to disease flares, rapidly improves pruritus and significantly enhances quality of life. Patients find the formulation easy to apply, which may result in improved adherence with the treatment regimen. Pimecrolimus, in contrast to topical corticosteroids (TCSs), does not induce skin atrophy or epidermal barrier dysfunction and is highly effective for the treatment of AD in sensitive skin areas. Furthermore, pimecrolimus reduces the incidence of skin infections compared with TCSs and is not associated with other TCS-related side effects such as striae, telangiectasia and hypothalamic-pituitary-adrenal axis suppression. An additional benefit of pimecrolimus is its substantial steroid sparing effect. On the basis of these data, a new treatment algorithm for patients with mild-to-moderate AD is proposed in which pimecrolimus is recommended as a first line therapy for patients with established mild AD at the first signs and symptoms of disease. Pimecrolimus is also recommended for mild-to-moderate AD after initial treatment with a TCS. After resolution of lesions, maintenance treatment with pimecrolimus may effectively prevent subsequent disease flares. In conclusion, the clinical profile of pimecrolimus suggests that it may be considered the drug of choice for the treatment of mild-tomoderate AD in children as well as adults and particularly in sensitive skin areas.

Key words: atopic dermatitis, pimecrolimus, topical calcineurin inhibitor, topical corticosteroid, treatment algorithm
A topic dermatitis (AD) is a chronic inflammatory, relapsing and pruritic skin disease [1-3]. AD is estimated to affect up to $25 \%$ of children and $2-10 \%$ of adults with the prevalence of disease having doubled or tripled in industrialized countries over the past 30 years $[4,5]$. The disease has a considerable impact on the quality of life (QoL) of both patients and their families [6].
Although the pathogenesis of AD is not completely understood, it is thought to result from a complex interplay between disruption of the epidermal barrier, immune dysfunction and environmental and infectious trigger factors $[4,7]$. The disturbance of the skin barrier leads to increased transepidermal water loss and scaly skin, an increased disposition to skin infections, and greater penetration of 
irritants and allergens into the skin [4, 7, 8]. Furthermore, recent research has indicated that the diversity in the skin microbial flora (i.e., the microbiome) is significantly decreased in affected skin areas of AD patients compared with controls and that changes in microbial diversity occur during disease flares which are dependent on previous $\mathrm{AD}$ treatments [9].

Since AD is a chronic and relapsing disease, a multi-faceted, long-term, clinical management approach is required. The therapeutic objectives should be to reduce the signs and symptoms of disease, such as eczema and pruritus, to repair the altered epidermal barrier and to improve QoL. Furthermore, treatments should aim to address the underlying immune dysfunction, which may prevent progression to disease flares and prolong remission periods $[4,7,10]$. Timely disease control is also advisable since early onset and disease severity may be regarded as risk factors for the so called "atopic march", i.e., the subsequent development and persistence of asthma and allergic rhinitis [11]. The term "atopic march" was coined to indicate that, based on the time of onset, skin involvement seems to predispose to the development of these other atopic diseases [7, 12]. Given the chronic nature of the disease, topical treatments for $\mathrm{AD}$ also need to be convenient to apply, safe and well tolerated. Educational courses should be offered to patients in addition to the treatment, given that these programs can improve the long-term management of $\mathrm{AD}$ [13].

Several treatment options are currently available for $\mathrm{AD}$ patients. Standard basic therapy for all AD patients involves optimal skin care and the identification and avoidance of trigger factors $[1,3,7]$. Emollients are the current mainstay for maintenance therapy of AD. They help to restore the impaired epidermal barrier function and thereby improve eczema and pruritus $[1,3,14,15]$. Anti-inflammatory treatments for AD include topical corticosteroids (TCSs) and topical calcineurin inhibitors (TCIs) [3]. Due to their broad anti-inflammatory actions, TCSs have been the cornerstone of topical AD therapy for the past 50 years and are recommended for treating disease flares $[3,16]$. More recently, two TCIs have become available for $\mathrm{AD}$ treatment $[3,14]$. Pimecrolimus $1 \%$ cream is indicated for the treatment of patients aged 2 years and over with mild-to-moderate $\mathrm{AD}$ where treatment with TCSs is either inadvisable or not possible. Tacrolimus ointment is indicated in moderateto-severe $\mathrm{AD}$ in patients aged 2 years and over who are not adequately responsive to or are intolerant of conventional therapies such as TCSs; the $0.1 \%$ ointment is for adolescents over 16 years and adults, whereas the $0.03 \%$ ointment can be used for children 2 years and older. TCIs have a more specific mode of action than TCSs. They selectively inhibit activation of $\mathrm{T}$ cells and mast cells and suppress the production of pro-inflammatory cytokines as well as other mediators of inflammation and pruritus $[17,18]$. Severe AD requiring UV therapy or treatment with immunomodulating drugs is not the focus of this paper [19].

The purpose of this review article is to evaluate clinical data on the use of pimecrolimus $1 \%$ cream in the management of mild-to-moderate $\mathrm{AD}$ in relation to the current medical needs of patients and in comparison with other topical $\mathrm{AD}$ treatments. On the basis of this review of published data and the clinical experience of the authors, a new practical algorithm for the treatment of patients with mild-to-moderate $\mathrm{AD}$ with pimecrolimus is proposed.

\section{Pimecrolimus 1\% cream and medical needs for the management of mild-to-moderate AD}

\section{Reduction in AD flares}

A distressing feature of $\mathrm{AD}$ is its chronically relapsing course characterized by eczema and pruritus. These disease flares have a major impact on various aspects of an AD patient's life, affecting school or work performance and productivity, disturbing sleep and altering self-esteem, mood and the ability to establish and maintain relationships [20]. Indeed, a survey has shown that most AD patients are either always or sometimes worried about their next $\mathrm{AD}$ flare [20]. Short courses of TCS therapy are commonly used as reactive first-line treatment for overt AD flares until the acute inflammation subsides [1, 3, 7, 21, 22].

Several studies have demonstrated that early treatment with pimecrolimus at the first signs or symptoms of $\mathrm{AD}$ can reduce the progression to disease flares and increase the interval between flares both in patients with or without active disease [23-26]. For example, there was a 50\% reduction in the mean number of flares over 6 months $(0.84 \mathrm{vs}$. $1.68, \mathrm{p}<0.0001)$ with pimecrolimus versus vehicle in children and a $30 \%$ reduction in adult patients $(0.97 \mathrm{vs} .1 .39$, $\mathrm{p}=0.0014$ ) with mild or moderate $\mathrm{AD}$ who were clear or almost clear of active skin lesions at study entry and who applied medication at the first signs and/or symptoms of new exacerbations. In both studies, the median time to first flare was three times longer with pimecrolimus (children: $>190$ vs. 59 days; adults: $>190$ vs. 67 days) $[25,26]$. These benefits also translated into a reduction in the need for TCS rescue medication (discussed in the section "Reduction in steroid use" below).

Studies have also been carried out to determine whether proactive maintenance treatment with anti-inflammatory agents is able to effectively and continuously control skin inflammation and prevent disease relapses [27]. Maintenance treatment is initiated once lesions have been successfully treated and involves long-term application of anti-inflammatory treatment to previously affected areas of skin [3]. The rationale for these investigations is that there is barrier dysfunction and subclinical inflammation even in normal-looking, non-lesional skin [4]. Although studies have shown that maintenance therapy with TCSs after the patient's $\mathrm{AD}$ has been stabilized may be beneficial for the prophylaxis of AD flares, TCSs are not recommended for long-term maintenance therapy due to the potential side effects associated with their chronic use (see section below "Other safety considerations") [14, 28-32].

Proactive maintenance treatment with pimecrolimus has been shown to be safe and to effectively prevent AD disease flares [33]. A total of 268 children and adolescents with $\mathrm{AD}$, who achieved disease remission or a decrease in the Investigator Global Assessment score of at least one point after open-label treatment with twice daily pimecrolimus for up to 6 weeks, were randomized to either once or twice daily pimecrolimus maintenance treatment for up to 16 weeks. During the open-label period, approximately half of the patients achieved disease remission and during maintenance treatment only a minority of patients in each treatment group had a disease relapse, defined as worsening of AD to a level where the use of TCS was needed (figure 1). 


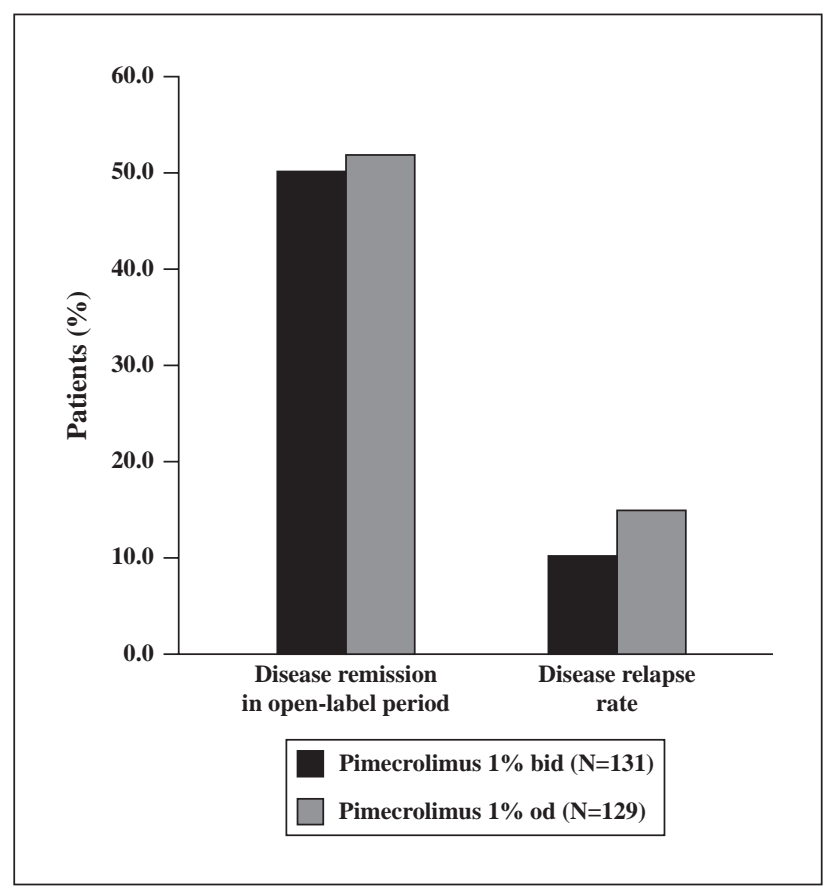

Figure 1. Disease remission during reactive treatment and relapse rates during maintenance treatment with pimecrolimus [33].

The time to disease relapse was not significantly different between the two groups (adjusted hazard ratio $0.64 ; 95 \% \mathrm{CI}$ $0.31-1.30 ; p=0.216$ ) [33]. On the basis of these findings, the authors proposed that a once daily maintenance regimen of pimecrolimus following successful treatment of an initial AD exacerbation was sufficient to prevent subsequent disease flares.

\section{Rapid relief of pruritus}

Persistent and intense pruritus is the most important clinical symptom in $\mathrm{AD}$ and may indicate impending $\mathrm{AD}$ flares. Pruritus may lead to sleeplessness and stress for both patients and their families [14]. Itching can lead to scratching which may further damage the disrupted skin barrier, resulting in additional inflammation and subsequent worsening of itching. As a consequence, a vicious itch/scratch cycle is initiated. Intense or sustained scratching can cause erosions and secondary infections. Reducing pruritus is therefore of paramount importance and, if done rapidly, may also improve compliance with treatment.

The cytokine, interleukin-31, which is produced by Th2 lymphocytes, has recently been identified as an important mediator of pruritus $[34,35]$. This suggests that the TCIs, which selectively inhibit $\mathrm{T}$ cell activation and cytokine production, may be more effective at relieving itching than other antipruritic therapies such as antihistamines.

Clinical investigations in both adults and children with mild-to-moderate AD and moderate/severe pruritus have shown that pimecrolimus rapidly improves pruritus within 48 hours of treatment being initiated [36, 37]. For example, in a study of 198 adults, more than half of pimecrolimustreated patients $(56 \%)$ had absent or mild pruritus within 48 hours, a significantly greater proportion than for vehicletreated patients $(34 \%, \mathrm{p}=0.003)$ and the significant difference between the treatment groups was maintained until the end of the 7-day study [36]. These data are supported by results from real-life studies involving over 10,000 patients which have also demonstrated a marked and rapid improvement in $\mathrm{AD}$-related symptoms with pimecrolimus in daily practice [38-40]. In a comparative study of pimecrolimus $1 \%$ cream and tacrolimus $0.03 \%$ ointment, a slightly greater proportion of children and adolescents with moderate AD treated with pimecrolimus had absent or mild pruritus four days after treatment had started. However, the difference between the treatments was not statistically significant (62\% vs. 49\%, respectively, $\mathrm{p}=0.182$ ) [41].

\section{Improvement in quality of life}

$\mathrm{AD}$ has a major impact on the lives of patients and their families $[6,42,43]$. Studies have shown that this condition affects everyday activities including school, work and social relationships and that $\mathrm{AD}$ patients may experience anxiety, depression and other psychological problems as a result of being affected by this stigmatizing skin condition [42]. The intense pruritus that continues during the day can worsen at night, leading to sleeplessness in over $60 \%$ of patients, which in turn can lead to fatigue and impaired functioning $[42,44]$.

Several short- and long-term studies have shown that pimecrolimus is associated with significant improvements in the QoL of AD patients and their parents compared with vehicle controls [23, 40, 45-48]. For example, in a 4-week study of 190 infants with AD, participants who received pimecrolimus were judged by their parents to have a significant improvement in the following QoL measures compared with those who were treated with vehicle: psychosomatic well-being: $14.6 \%$ vs. $6.2 \%$; effects on social life: $6.7 \% \mathrm{vs}$. $2.3 \%$; confidence in medical treatment: $10.0 \%$ vs. $3.7 \%$; emotional coping: $16.1 \%$ vs. $6.5 \%$; acceptance of disease: $19.6 \%$ vs. $7.0 \%$ [46].

Limited data exist which compare QoL outcomes between TCIs and TCSs. The results of one 4-month observational study showed that $77 \%$ of pimecrolimus-treated patients reported an improvement in QoL compared with $42 \%$ of TCS-treated patients [49].

\section{Maintenance of treatment adherence}

Since patients with AD have to regularly treat their skin for several years, AD therapies need to encourage good compliance in addition to providing adequate efficacy. Maintaining treatment adherence is essential in ensuring the success of the regimen.

Factors that may influence adherence include formulation characteristics and handling properties of the treatment. A comparison of pimecrolimus and TCSs in a large observation study of 3,200 patients showed that patients preferred pimecrolimus to TCSs with around two times as many patients considering that pimecrolimus was easy to apply compared with TCSs [49].

Safety and tolerability issues also affect adherence to treatment regimens. Corticophobia is a known issue associated with the use of TCSs and leads to suboptimal treatment in many patients [14]. Studies have shown that over $70 \%$ of 
parents and caregivers of children with $\mathrm{AD}$ are concerned about the side effects of TCSs and this may reduce adherence with this therapy [50-53]. Further details on the safety of topical anti-inflammatory therapies for AD are provided in the section below, "Other safety considerations".

\section{No induction of skin atrophy or impairment of epidermal barrier}

AD treatments should not induce skin atrophy and should not impair the already altered epidermal barrier, in order to prevent penetration and permeation of irritants and allergens. Long-term use of TCSs can cause skin atrophy, mainly as a result of inhibition of fibroblast function and a subsequent reduction in the production of collagen [54]. In contrast, pimecrolimus has a more selective mode of action and does not induce skin atrophy as it has no effect on fibroblasts at clinically relevant concentrations [55].

The results of several clinical studies have confirmed that, unlike TCSs, pimecrolimus is not associated with the development of skin atrophy or impairment of the epidermal barrier. A randomized 4-week clinical study showed that both triamcinolone acetonide and betamethasone-17valerate induced a significant reduction in skin thickness compared with pimecrolimus of $12.2 \%$ and $7.9 \%$, respectively $(\mathrm{p}<0.001)$ with significant differences appearing after only eight days of treatment [56]. Another 6-week clinical study showed that pimecrolimus may reverse TCSinduced skin atrophy with a significantly greater proportion of pimecrolimus-treated patients experiencing improved skin atrophy than those treated with vehicle $(46.5 \%$ vs. $17.6 \%, \mathrm{p}=0.002$ ) [57]. A further 3-week study showed that the epidermal barrier was improved upon pimecrolimus treatment but not with betamethasone-17-valerate. Regular and continuous extracellular lipid bilayer structures were observed in the stratum corneum after treatment with pimecrolimus, whereas the skin barrier structure and lipid bilayer formation were highly irregular after betamethasone-17valerate [58].

Recent data suggest that pimecrolimus may be able to restore the epidermal barrier by its effect on the expression of genes, which are essential for normal skin barrier function, whereas TCSs have an overall less favorable impact on these genes (table 1) [59,60]. For example, betamethasone17-valerate, in contrast to pimecrolimus, was shown to cause a significant reduction in the expression of involucrin and small proline-rich proteins (which bind to ceramides) in skin samples from AD lesions [60].

\section{Treatment of sensitive skin areas}

AD commonly occurs in thin and sensitive areas of skin, such as the face (eyelids, perioral region), neck, genital area, axilla region and inguinal folds. Given that TCIs do not cause skin atrophy, they are particularly useful for the treatment of AD in such areas and are recommended as first-line therapy in these areas by European guidelines [1, 3, 61]. An additional benefit of TCIs for the treatment of eyelid dermatitis - which affects around $80 \%$ of patients - is that they are not associated with an increased risk for cataracts or glaucoma [57].

Several randomized clinical trials and real-life studies involving over 3500 patients have shown that pimecrolimus is highly effective for the treatment of facial dermatitis in both adults and children [38, 57, 62-64]. Accordingly, a significantly greater proportion of adults were cleared or almost cleared of facial $\mathrm{AD}(47 \%$ vs. $16 \%, \mathrm{p}<0.001)$ and achieved clearance of eyelid dermatitis $(45 \%$ vs. $19 \%, \mathrm{p}<0.001)$ after 6 weeks of treatment with pimecrolimus compared with vehicle [57]. Similarly, six weeks of pimecrolimus treatment in children led to a greater proportion of patients being cleared or almost cleared of facial AD compared with vehicle $(74.5 \%$ vs. $51 \%, \mathrm{p}<0.001)$ [62].

The results of a comparative study of pimecrolimus $1 \%$ cream and tacrolimus $0.03 \%$ ointment in pediatric patients with moderate $\mathrm{AD}$ suggested that pimecrolimus might be more effective for the treatment of the head and neck area. There was a 54\% reduction from baseline in the proportion of the head and neck area that was affected by $\mathrm{AD}$ with pimecrolimus compared with a $35 \%$ reduction with tacrolimus, although the difference between the treatments was not statistically significant [41].

\section{Reduction of skin infections}

$\mathrm{AD}$ patients are known to be more susceptible to bacterial, fungal and viral skin infections than those without the disease $[65,66]$. Due to the impaired epidermal barrier function and the decreased expression of antimicrobial proteins in acute eczema, the epidermis is colonized at a high rate with microorganisms such as Staphylococcus aureus which is the most common bacterial pathogen [67]. Recent research has shown that there is a decrease in the normal diversity of the skin microbiome during disease flares, ultimately leading to an increase in the levels of $S$. aureus [9]. Treatment that is associated with an improvement of eczema results in a restoration of the diversity of the skin microbiome [9].

Table 1. Gene expression profile analysis of lesional AD skin samples after topical treatment with either pimecrolimus $1 \%$ cream or betamethasone-17-valerate [60].

\begin{tabular}{|lcc|}
\hline & Pimecrolimus & Betamethasone-17-valerate \\
\hline Markers of immune cells and inflammation & $(\downarrow)$ & $\downarrow \downarrow$ \\
\hline Filaggrin \& loricrin & $\uparrow$ & $\uparrow$ \\
\hline Involucrin \& small proline-rich proteins (bind ceramides) & \pm 0 & $\downarrow \downarrow \downarrow$ \\
\hline Enzymes for lipid synthesis & \pm 0 & $\downarrow \downarrow \downarrow$ \\
\hline
\end{tabular}

$\downarrow \downarrow \downarrow$, significant reduction; $(\downarrow)$, minor reduction; $\uparrow$, slight increase; \pm 0 , minor effects only; AD, atopic dermatitis. 
The potent anti-inflammatory actions of TCSs may increase susceptibility to bacterial, viral, and fungal infections with findings from animal models showing an impairment of the function of dendritic cells and a marked decrease in antimicrobial peptide expression [68-70]. Unlike TCSs, pimecrolimus does not affect the function of dendritic cells. Furthermore it may enhance the expression of antimicrobial proteins in keratinocytes and increase their capacity to inhibit the growth of $S$. aureus $[69,71]$. Accordingly, the use of pimecrolimus is not associated with an increase in the risk of skin infection. The results of a clinical study showed that half as many patients who were treated with pimecrolimus for 12 months experienced skin infections compared with TCS-treated patients ( $15.4 \%$ vs. 29.7\%) [72]. These data are supported by those from a real-life study which showed a lower rate of skin infections in patients treated with pimecrolimus over a 6-month period than the rate that would be expected in patients with $\mathrm{AD}$ (table 2) [38].

Treatment with short-term topical antiseptics or systemic antibiotics/antivirals is necessary when skin infections do occur, depending on the severity and distribution of the disease [3].

\section{Other safety considerations}

The safety of $\mathrm{AD}$ treatments is of particular importance given that the chronic and relapsing nature of the disease means that therapy will need to be regularly applied over many years.

The side effects associated with TCSs depend on the specific TCS used, its potency and the site of application and they are considered to be related to the unspecific mode of action of these anti-inflammatory agents [73, 74]. Local side effects associated with prolonged TCS use include atrophy, striae, petechiae, telangiectasia and acne [7, 73]. Systemic side effects such as hypothalamic-pituitary-adrenal axis (HPA) suppression are rare and usually restricted to the use of potent or very potent TCSs $[3,7,73]$.

The most common side effect with TCIs is transient warmth or a burning sensation at the application site during the first few days of treatment [75-77]. Accordingly, new data indicate that calcineurin inhibitors may directly affect cutaneous nerves by modulating the function of ion channels such as TRPV1 (transient receptor potential subtype vanilloid 1), initially leading to the release of substance P (SP) and subsequently inhibiting SP re-accumulation. This may explain the initial SP-mediated burning sensation after the application of TCIs, as well as the subsequent anti-pruritic activity $[78,79]$. The important role of SP as a mediator of itching in $\mathrm{AD}$ is further supported by the finding that targeting the receptor for SP (neurokinin receptor 1 (NRK1)) with aprepitant, a specific NKR1 inhibitor, leads to a significant improvement of pruritus in $\mathrm{AD}$ patients [80].
The local application site reactions associated with TCIs are less common and of shorter duration with pimecrolimus compared with tacrolimus, which may help to improve compliance with the treatment. In a study of 141 pediatric $\mathrm{AD}$ patients, the incidence of erythema/irritation at day 4 of treatment was significantly lower with pimecrolimus $1 \%$ cream compared with tacrolimus $0.03 \%$ ointment ( $8 \%$ vs. $19 \%, \mathrm{p}=0.039)$. Furthermore, significantly fewer pimecrolimus-treated patients experienced these side effects for more than 30 minutes compared with those treated with tacrolimus $0.03 \%$ ointment $(0 \% v s .85 \%$, $\mathrm{p}<0.001$ ) [41].

Due to their higher molecular weight and lipophilicity, TCIs penetrate much less through the skin than TCSs and so have a much lower risk of systemic side effects [75, 81]. Pharmacokinetic studies of pimecrolimus have shown minimal systemic exposure irrespective of age and disease extent [82-84]. Comparing the TCIs, pimecrolimus is 8-fold more lipophilic than tacrolimus, which increases its affinity for the skin and leads to 10-fold lower permeation through the epidermis, resulting in much lower systemic exposure $[81,85]$. This lower systemic exposure with pimecrolimus may ultimately result in a more favorable safety profile compared with tacrolimus.

Long-term clinical and epidemiological studies have shown that pimecrolimus is not associated with an increased cancer risk, possibly due to a lack of systemic accumulation $[75,86]$. For example, a nested case-control study of a cohort of 293,253 patients with AD, 294 of whom developed lymphoma, showed that the risk of lymphoma was not increased in patients treated with either pimecrolimus (odds ratio: $0.8 ; 95 \%$ CI: $0.4-1.6$ ) or tacrolimus (odds ratio: $0.8 ; 95 \%$ CI: $0.4-1.7$ ). In contrast, the risk of lymphoma was increased in patients taking oral steroids (odds ratio: 1.5; 95\% CI: 1.0-2.4) [87]. In addition, a recent study demonstrated that the incidence of lymphoma in patients being treated with pimecrolimus is 54-fold lower than in the general US population [88]. Although there have been anecdotal reports of cutaneous lymphoma in patients being treated with a TCI, it is considered that these patients may have been misdiagnosed with $\mathrm{AD}$ and may have actually had a pre-existing cutaneous lymphoma [89]. Furthermore, there is currently no evidence that the topical use of calcineurin inhibitors such as pimecrolimus is associated with an increased risk for the development of melanoma or non-melanoma skin cancer [90].

\section{Reduction in steroid use}

Another potential benefit of TCIs is their steroid sparing effect. Although TCSs remain the mainstay of AD treatment, the side effects associated with their prolonged use can result in reluctance towards their use, which may in turn

Table 2. Skin infection rates with pimecrolimus compared with expected rates in AD patients.

\begin{tabular}{|lcc|}
\hline Skin infection & Pimecrolimus (\% patients) & Expected incidence (\% patients) \\
\hline Herpes simplex & $2.1[72]$ & $6-10[92-4]$ \\
\hline Molluscum contagiosum & $1.2[72]$ & $4-13[93,95]$ \\
\hline Viral wart (human papillomavirus infections) & $0.3[72]$ & $4-17[92,93]$ \\
\hline
\end{tabular}


lead to non-compliance with the therapeutic regimen and consequent treatment failure [20, 50-53]. In addition, many AD patients will have co-morbidities such as asthma and allergic rhinitis, which also need corticosteroid treatment $[11,91]$.

Clinical investigations and real-life studies of short and long-term intermittent use of pimecrolimus in children and adults have consistently reported a reduced requirement for TCSs [23-26, 38]. This steroid sparing effect is illustrated by the results of a study in 713 children with AD who received pimecrolimus or vehicle at the first signs or symptoms of an AD flare. Over 12 months, 57.4\% pimecrolimus-treated patients did not require TCS therapy to control a disease flare compared with $31.6 \%$ of vehicle-treated patients [24]. In addition, a 5-year open label comparison of pimecrolimus $1 \%$ cream and low to medium potency TCSs in infants aged 3-<12 months with mildto-moderate AD (the "Petite study") has demonstrated that the two treatments have similar efficacy, although pimecrolimus was associated with a substantial steroid sparing effect (Data on file, Meda).

\section{New AD treatment algorithm}

In order to guide physicians involved in managing patients with mild-to-moderate AD, the authors developed a new algorithm for the treatment of this disease with pimecrolimus, based on the data discussed in this article and their own clinical experience (figure 2). The authors also recommend general skin care measures for all patients, such as bathing in lukewarm water for 5 minutes each day or every other day, as this will assist in hydrating and cleansing the skin as well as removing crusts and/or scales [3]. Moisturizers and emollients should be applied liberally after patting

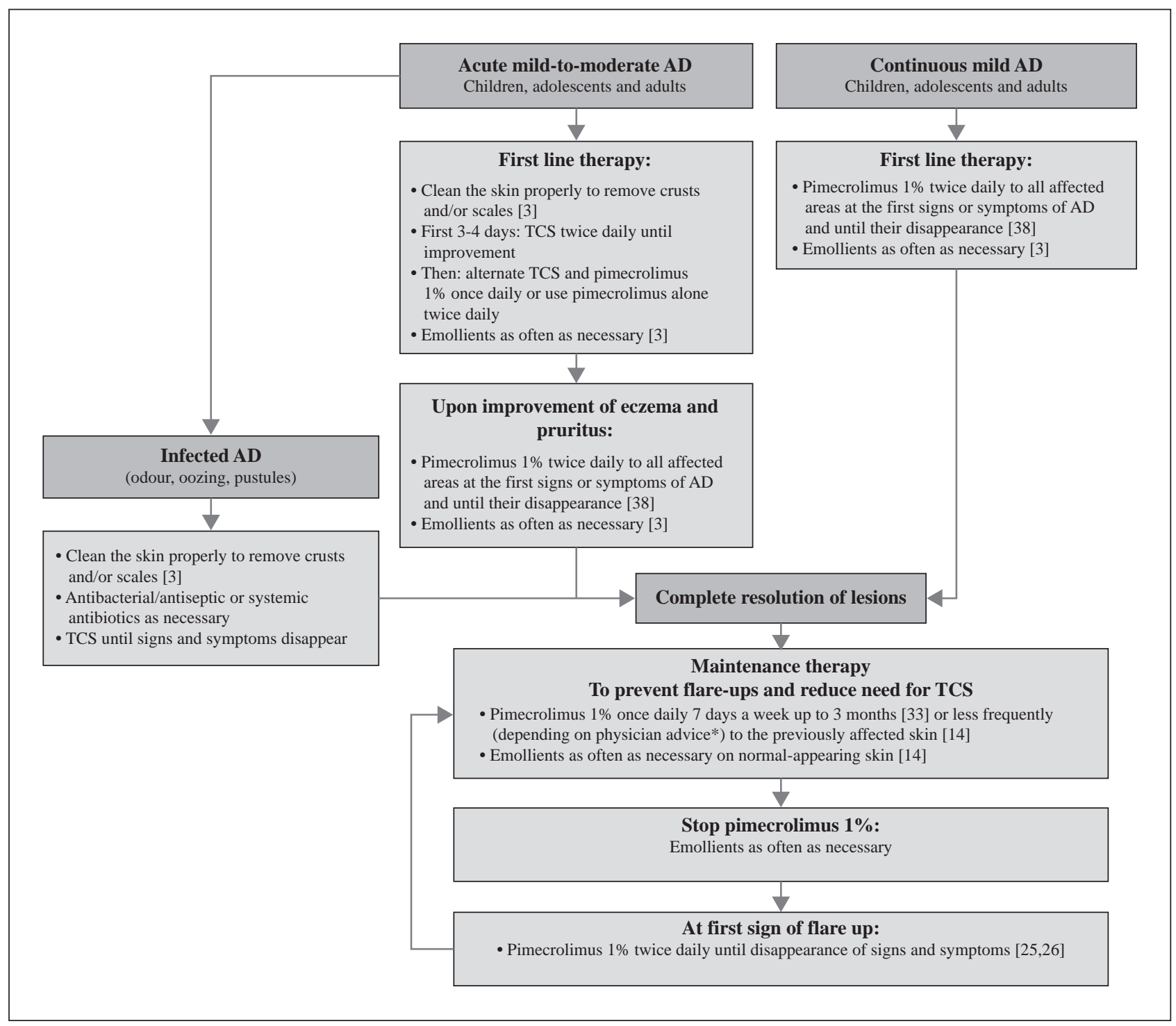

Figure 2. Treatment algorithm for mild-to-moderate AD.

* Not included in the Summary of Product Characteristics for pimecrolimus.

AD, atopic dermatitis; TCS, topical corticosteroid. 
the patient's skin dry with a towel to prevent moisture loss and skin drying [3]. The authors strongly recommend that patients should be regularly assessed in order to evaluate the efficacy and tolerability of treatment.

In the current treatment algorithm, pimecrolimus $1 \%$ cream twice daily is recommended as a first line therapy for patients with established, continuous, mild $\mathrm{AD}$, at the first signs and symptoms of disease. This is based on data from real-life studies of pimecrolimus, which, for example, have shown an improvement in Investigator Global Assessment scores within one week of initiating treatment in $43 \%$ of patients with mild disease [38].

In patients with acute mild-to-moderate $\mathrm{AD}$, TCSs twice daily are recommended for the first 3-4 days to rapidly reduce inflammation. Following this, TCS and pimecrolimus $1 \%$ cream should each be used once daily, or pimecrolimus $1 \%$ cream can be initiated twice daily after stopping treatment with the TCS. This recommendation is based on the clinical experience of the authors. Once the patient's eczema and pruritus have improved, pimecrolimus $1 \%$ cream twice daily is recommended until the signs or symptoms disappear.

For patients with relapsing $\mathrm{AD}$, pimecrolimus $1 \%$ cream should be applied as maintenance therapy to the previously affected skin following complete resolution of lesions, either once daily for seven days a week for up to three months or less frequently, depending on the advice of the treating physician. The former regimen was shown to effectively prevent subsequent disease flares following successful treatment of active AD lesions [33]. For patients without active disease, early treatment of signs or symptoms of an $\mathrm{AD}$ flare with pimecrolimus $1 \%$ cream twice daily is recommended since this has been shown to reduce progression to flares, decrease TCS exposure and prolong remission time in this setting $[25,26]$.

Finally, the authors recommend that patients with infected mild-to-moderate $\mathrm{AD}$ should receive short-term topical antiseptics or systemic antibiotics/antivirals as necessary and should continue their TCS until signs and symptoms disappear (figure 2). As previously discussed, patients with $\mathrm{AD}$ are more susceptible to bacterial, fungal and viral skin infections and these infections can lead to deterioration of the skin lesions $[1,7,14]$.

\section{Conclusions}

$\mathrm{AD}$ is a common skin disorder that can have a major impact on a patient's QoL. Treatments for AD need to rapidly control symptoms of the disease, improve QoL and prevent exacerbations. Given the chronic and relapsing nature of the disease, therapies need to encourage good compliance and be well tolerated.

Pimecrolimus is recommended in our new treatment algorithm for patients with mild-to-moderate $\mathrm{AD}$ following initial treatment with TCSs and may also be beneficial as maintenance treatment for the prevention of disease flareups. Pimecrolimus improves patients' QoL and also has a steroid sparing effect, which is particularly beneficial for patients with co-morbid conditions such as asthma and allergic rhinitis, which are also treated with corticosteroids. Unlike TCSs, pimecrolimus does not cause epidermal barrier dysfunction or skin atrophy and so is suitable for use on sensitive skin areas such as the face and around the eyes and flexures. Compared with TCSs, pimecrolimus has a more favorable safety profile, does not increase the likelihood of skin infections and is preferred by patients. Pimecrolimus is also associated with fewer application site reactions and has a lower systemic exposure compared with tacrolimus. Taken together, these findings suggest that pimecrolimus $1 \%$ cream may be considered the drug of choice for the treatment of patients with mild-to-moderate $\mathrm{AD}$ in children as well as adults and particularly in sensitive skin areas.

Disclosure. Financial support: Editorial assistance in the preparation of this manuscript was provided by David Harrison, Medscript Communications, funded by Meda Pharma GmbH \& Co. KG. Conflict of interest: Thomas Luger: Speaker and advisory board member for Meda; Julien Lambert: Speaker and advisory board member for Meda; Marianne Morren: Advisory board member for Meda. Grant for attending EADV 2012 meeting 2012; Mireille Ruer: Speaker for Meda; Thomas Werfel: Advisor for Meda. Other authors: none.

\section{References}

1. Akdis CA, Akdis M, Bieber $T$, et al. Diagnosis and treatment of atopic dermatitis in children and adults: European Academy of Allergology and Clinical Immunology/American Academy of Allergy, Asthma and Immunology/PRACTALL Consensus Report. J Allergy Clin Immunol 2006; 118: 152-69.

2. Darsow $U$, Wollenberg $A$, Simon $D$, et al. ETFAD/EADV eczema task force 2009 position paper on diagnosis and treatment of atopic dermatitis. J Eur Acad Dermatol Venereol 2010; 24:317-28.

3. Ring J, Alomar A, Bieber $T$, et al. Guidelines for treatment of atopic eczema (atopic dermatitis) part I. J Eur Acad Dermatol Venereol 2012; 26: 1045-60.

4. Bieber T. Atopic dermatitis. N Engl J Med 2008; 358: 1483-94.

5. Odhiambo JA, Williams HC, Clayton TO, Robertson CF, Asher MI. Global variations in prevalence of eczema symptoms in children from ISAAC Phase Three. J Allergy Clin Immunol 2009; 124: 1251-8.

6. McKenna SP, Doward LC. Quality of life of children with atopic dermatitis and their families. Curr Opin Allergy Clin Immunol 2008; 8: 228-31.

7. Watson W, Kapur S. Atopic dermatitis. Allergy Asthma Clin Immunol 2011;7 Suppl 1: S4.

8. Barnetson RS, Rogers $M$. Childhood atopic eczema. BM 2002; 324: 1376-9.

9. Kong HH, Oh J, Deming C, et al. Temporal shifts in the skin microbiome associated with disease flares and treatment in children with atopic dermatitis. Genome Res 2012; 22: 850-9.

10. Boguniewicz M, Leung DY. Recent insights into atopic dermatitis and implications for management of infectious complications. J Allergy Clin Immunol 2010; 125: 4-13.

11. Spergel JM. Epidemiology of atopic dermatitis and atopic march in children. Immunol Allergy Clin North Am 2010; 30: 269-80.

12. Spergel JM. From atopic dermatitis to asthma: the atopic march. Ann Allergy Asthma Immunol 2010; 105: 99-106.

13. Staab $D$, Diepgen $T L$, Fartasch $M$, et al. Age related, structured educational programmes for the management of atopic dermatitis in children and adolescents: multicentre, randomised controlled trial. BM 2006; 332: 933-8.

14. Plotz SG, Ring J. What's new in atopic eczema? Expert Opin Emerg Drugs 2010; 15: 249-67.

15. Cork M, Danby S. Skin barrier breakdown: a renaissance in emollient therapy. Br J Nurs 2009; 18: 872-7. 
16. Kalavala $M$, Dohil MA. Calcineurin inhibitors in pediatric atopic dermatitis: a review of current evidence. Am J Clin Dermatol $2011 ; 12: 15-24$.

17. Hultsch T, Müller KD, Meingassner JG, Grassberger M, Schopf RE, Knop J. Ascomycin macrolactam derivative SDZ ASM 981 inhibits the release of granule-associated mediators and of newly synthesized cytokines in RBL $2 \mathrm{H} 3$ mast cells in an immunophilin-dependent manner. Arch Dermatol Res 1998; 290: 501-7.

18. Grassberger $M$, Baumruker $T$, Enz $A$, et al. A novel antiinflammatory drug, SDZ ASM 981, for the treatment of skin diseases: in vitro pharmacology. Br J Dermatol 1999; 141:264-73.

19. Ring J, Alomar A, Bieber $T$, et al. Guidelines for treatment of atopic eczema (atopic dermatitis) Part II. J Eur Acad Dermatol Venereol 2012; 26: 1176-93.

20. Zuberbier T, Orlow SJ, Paller AS, et al. Patient perspectives on the management of atopic dermatitis. J Allergy Clin Immunol 2006; 118: 226-32.

21. Hoare C, Li Wan PA, Williams H. Systematic review of treatments for atopic eczema. Health Technol Assess 2000; 4: 1-191.

22. Hanifin JM, Cooper KD, Ho VC, et al. Guidelines of care for atopic dermatitis, developed in accordance with the American Academy of Dermatology (AAD)/American Academy of Dermatology Association "Administrative Regulations for Evidence-Based Clinical Practice Guidelines". J Am Acad Dermatol 2004; 50: 391-404.

23. Meurer $M$, Fölster-Holst $R$, Wozel $G$, Weidinger $G$, Junger $M$, Bräutigam $M$. Pimecrolimus cream in the long-term management of atopic dermatitis in adults: a six-month study. Dermatology 2002; 205: 271-7.

24. Wahn U, Bos JD, Goodfield $M$, et al. Efficacy and safety of pimecrolimus cream in the long-term management of atopic dermatitis in children. Pediatrics 2002; 110: e2.

25. Sigurgeirsson $B$, Ho V, Ferrandiz $C$, Andriano K, Grinienko A, Jimenez P. Effectiveness and safety of a prevention-of-flare-progression strategy with pimecrolimus cream $1 \%$ in the management of paediatric atopic dermatitis. J Eur Acad Dermatol Venereol 2008; 22: 1290-301.

26. Gollnick $H$, Kaufmann $R$, Stough $D$, et al. Pimecrolimus cream $1 \%$ in the long-term management of adult atopic dermatitis: prevention of flare progression. A randomized controlled trial. Br J Dermatol 2008; 158: 1083-93

27. Schmitt J, von Kobyletzki L, Svensson A, Apfelbacher C. Efficacy and tolerability of proactive treatment with topical corticosteroids and calcineurin inhibitors for atopic eczema: systematic review and meta-analysis of randomized controlled trials. $\mathrm{Br} J$ Dermatol 201 1; 164:415-28.

28. Berth-Jones J, Damstra RJ, Golsch S, et al. Twice weekly fluticasone propionate added to emollient maintenance treatment to reduce risk of relapse in atopic dermatitis: randomised, double blind, parallel group study. BM 2003; 326: 1367.

29. Glazenburg EJ, Wolkerstorfer A, Gerretsen AL, Mulder PG, Oranje AP. Efficacy and safety of fluticasone propionate $0.005 \%$ ointment in the long-term maintenance treatment of children with atopic dermatitis: differences between boys and girls? Pediatr Allergy Immunol 2009; 20: 59-66.

30. Hanifin J, Gupta AK, Rajagopalan R. Intermittent dosing of fluticasone propionate cream for reducing the risk of relapse in atopic dermatitis patients. Br J Dermatol 2002; 147: 528-37.

31. Peserico A, Städtler G, Sebastian M, Fernandez RS, Vick K, Bieber $\mathrm{T}$. Reduction of relapses of atopic dermatitis with methylprednisolone aceponate cream twice weekly in addition to maintenance treatment with emollient: a multicentre, randomized, double-blind, controlled study. Br J Dermatol 2008; 158: 801-7.

32. Van Der Meer JB, Glazenburg EJ, Mulder PG, Eggink HF, Coenraads PJ. The management of moderate to severe atopic dermatitis in adults with topical fluticasone propionate. The Netherlands Adult Atopic Dermatitis Study Group. Br J Dermatol 1999; 140: $1114-21$.

33. Ruer-Mulard $M$, Aberer $W$, Gunstone $A$, et al. Twice-daily versus once-daily applications of pimecrolimus cream $1 \%$ for the prevention of disease relapse in pediatric patients with atopic dermatitis. Pediatr Dermatol 2009; 26: 551-8.

34. Dillon SR, Sprecher C, Hammond A, et al. Interleukin 31, a cytokine produced by activated T cells, induces dermatitis in mice. Nat Immunol 2004; 5: 752-60.
35. Sonkoly E, Muller A, Lauerma Al, et al. IL-31: a new link between $\mathrm{T}$ cells and pruritus in atopic skin inflammation. J Allergy Clin Immunol 2006; 117:411-7.

36. Kaufmann $R$, Bieber $T$, Helgesen $A L$, et al. Onset of pruritus relief with pimecrolimus cream $1 \%$ in adult patients with atopic dermatitis: a randomized trial. Allergy 2006; 61:375-81.

37. Fowler J, Johnson A, Chen M, Abrams K. Improvement in pruritus in children with atopic dermatitis using pimecrolimus cream $1 \%$. Cutis 2007; 79: 65-72

38. Lübbe J, Friedlander SF, Cribier B, et al. Safety, efficacy, and dosage of $1 \%$ pimecrolimus cream for the treatment of atopic dermatitis in daily practice. Am J Clin Dermatol 2006; 7: 121-31.

39. Luger TA, Gollnick H, Schwennesen T, Bextermöller R, Freytag $S$, Bräutigam M. Safety and efficacy of pimecrolimus cream $1 \%$ in the daily practice: results of a patient self-observation study in patients with atopic dermatitis. J Dtsch Dermatol Ges 2007; 5: 908-14.

40. Sunderkötter $C$, Weiss JM, Bextermöller $R$, Loffler $H$, Schneider $D$. Post-marketing surveillance on treatment of 5,665 patients with atopic dermatitis using the calcineurin inhibitor pimecrolimus: positive effects on major symptoms of atopic dermatitis and on quality of life. J Dtsch Dermatol Ges 2006; 4: 301-6.

41. Kempers $S$, Boguniewicz $M$, Carter $E$, et al. A randomized investigator-blinded study comparing pimecrolimus cream $1 \%$ with tacrolimus ointment $0.03 \%$ in the treatment of pediatric patients with moderate atopic dermatitis. J Am Acad Dermatol 2004; 51:515-25.

42. Lewis-Jones $S$. Quality of life and childhood atopic dermatitis: the misery of living with childhood eczema. Int J Clin Pract 2006; 60: 98492.

43. Katsarou A, Armenaka M. Atopic dermatitis in older patients: particular points. J Eur Acad Dermatol Venereol 2011 ; 25: 12-8.

44. Leo HL, Bender BG, Leung SB, Tran ZV, Leung DY. Effect of pimecrolimus cream $1 \%$ on skin condition and sleep disturbance in children with atopic dermatitis. J Allergy Clin Immunol 2004; 1 14:691-3.

45. Whalley $D$, Huels J, McKenna SP, Van Assche $D$. The benefit of pimecrolimus (Elidel, SDZ ASM 981) on parents' quality of life in the treatment of pediatric atopic dermatitis. Pediatrics 2002; 110 : 1 133-6.

46. Staab D, Kaufmann R, Bräutigam M, Wahn U. Treatment of infants with atopic eczema with pimecrolimus cream $1 \%$ improves parents' quality of life: a multicenter, randomized trial. Pediatr Allergy Immunol 2005; 16: 527-33.

47. McKenna SP, Whalley $D$, de Prost $Y$, et al. Treatment of paediatric atopic dermatitis with pimecrolimus (Elidel, SDZ ASM 981): impact on quality of life and health-related quality of life. J Eur Acad Dermatol Venereol 2006; 20: 248-54.

48. Ingram JR, Martin JA, Finlay AY. Impact of topical calcineurin inhibitors on quality of life in patients with atopic dermatitis. Am J Clin Dermatol 2009; 10: 229-37.

49. Gollnick H, Luger T, Freytag S, Bräutigam M. StabiEL: stabilization of skin condition with Elidel-a patients' satisfaction observational study addressing the treatment, with pimecrolimus cream, of atopic dermatitis pretreated with topical corticosteroid. J Eur Acad Dermatol Venereol 2008; 22: 1319-25.

50. Fischer G. Compliance problems in paediatric atopic eczema. Australas J Dermatol 1996; 37 Suppl 1: S10-3.

51. Aubert-Wastiaux H, Moret L, Le Rhun A, et al. Topical corticosteroid phobia in atopic dermatitis: a study of its nature, origins and frequency. Br J Dermatol 2011 ; 165: 808-14.

52. Charman $C R$, Morris $A D$, Williams $H C$. Topical corticosteroid phobia in patients with atopic eczema. Br J Dermatol 2000; 142: 931-6.

53. Fukaya $M$. Why do patients with atopic dermatitis refuse to apply topical corticosteroids? Dermatology 2000; 201:242-5.

54. Nuutinen $P$, Riekki $R$, Parikka $M$, et al. Modulation of collagen synthesis and mRNA by continuous and intermittent use of topical hydrocortisone in human skin. Br J Dermatol 2003; 148: 39-45.

55. Grassberger $M$, Steinhoff $M$, Schneider $D$, Luger TA. Pimecrolimus - an anti-inflammatory drug targeting the skin. Exp Dermatol 2004; 13:721-30.

56. Queille-Roussel C, Paul C, Duteil L, et al. The new topical ascomycin derivative SDZ ASM 981 does not induce skin atrophy when applied to normal skin for 4 weeks: a randomized, double-blind controlled study. Br J Dermatol 2001; 144: 507-13. 
57. Murrell DF, Calvieri S, Ortonne JP, et al. A randomized controlled trial of pimecrolimus cream $1 \%$ in adolescents and adults with head and neck atopic dermatitis and intolerant of, or dependent on, topical corticosteroids. Br J Dermatol 2007; 157: 954-9.

58. Jensen JM, Pfeiffer $S$, Witt $M$, et al. Different effects of pimecrolimus and betamethasone on the skin barrier in patients with atopic dermatitis. J Allergy Clin Immunol 2009; 124: R19-28.

59. Grzanka A, Zebracka-Gala J, Rachowska R, Bozek A, Kowalska $M$, Jarzab J. The effect of pimecrolimus on expression of genes associated with skin barrier dysfunction in atopic dermatitis skin lesions. Exp Dermatol 2012; 21 : 184-8.

60. Jensen JM, Scherer A, Wanke $C$, et al. Gene expression is differently affected by pimecrolimus and betamethasone in lesional skin of atopic dermatitis. Allergy 2012;67: 413-23.

61. Draelos ZD. Use of topical corticosteroids and topical calcineurin inhibitors for the treatment of atopic dermatitis in thin and sensitive skin areas. Curr Med Res Opin 2008; 24: 985-94.

62. Hoeger $\mathrm{PH}$, Lee $\mathrm{KH}$, Jautova J, et al. The treatment of facial atopic dermatitis in children who are intolerant of, or dependent on, topical corticosteroids: a randomized, controlled clinical trial. $\mathrm{Br} J$ Dermatol 2009; 160: 415-22.

63. Ring J, Abraham A, de Cuyper $C$, et al. Control of atopic eczema with pimecrolimus cream $1 \%$ under daily practice conditions: results of a > 2000 patient study. J Eur Acad Dermatol Venereol 2008; 22: 195 203.

64. Zuberbier T, Bräutigam M. Long-term management of facial atopic eczema with pimecrolimus cream $1 \%$ in paediatric patients with mild to moderate disease. J Eur Acad Dermatol Venereol 2008; 22: 718-21.

65. Lübbe J. Secondary infections in patients with atopic dermatitis. Am J Clin Dermatol 2003; 4: 641-54.

66. Wollenberg A, Wetzel S, Burgdorf WH, Haas J. Viral infections in atopic dermatitis: pathogenic aspects and clinical management. $J$ Allergy Clin Immunol 2003; 112: 667-74.

67. Leung DY. Infection in atopic dermatitis. Curr Opin Pediatr 2003; 15:399-404.

68. Wong VK, Della CC, Schonfeld S, Mastrangelo AM, Lebwohl M. Use and abuse of topical corticosteroids in infections of the skin and related structures. J Drugs Dermatol 2003; 2: 268-76.

69. Hoetzenecker W, Meingassner JG, Ecker R, Stingl G, Stuetz A, Elbe-Burger A. Corticosteroids but not pimecrolimus affect viability, maturation and immune function of murine epidermal Langerhans cells. J Invest Dermatol 2004; 122: 673-84.

70. Jensen JM, Ahrens K, Meingassner J, et al. Differential suppression of epidermal antimicrobial protein expression in atopic dermatitis and in EFAD mice by pimecrolimus compared to corticosteroids. Exp Dermatol 201 1; 20: 783-8.

71. Büchau AS, Schauber J, Hultsch T, Stuetz A, Gallo RL. Pimecrolimus enhances TLR2/6-induced expression of antimicrobial peptides in keratinocytes. J Invest Dermatol 2008; 128: 2646-54.

72. Luger TA, Lahfa $M$, Fölster-Holst $R$, et al. Long-term safety and tolerability of pimecrolimus cream $1 \%$ and topical corticosteroids in adults with moderate to severe atopic dermatitis. J Dermatolog Treat 2004; 15: 169-78.

73. Hengge UR, Ruzicka T, Schwartz RA, Cork M. Adverse effects of topical glucocorticosteroids. J Am Acad Dermatol 2006; 54: 1-15.

74. Hultsch T, Kapp A, Spergel J. Immunomodulation and safety of topical calcineurin inhibitors for the treatment of atopic dermatitis. Dermatology 2005; 211 : 174-87.

75. Langley RG, Luger TA, Cork M, Schneider D, Paul C. An update on the safety and tolerability of pimecrolimus cream $1 \%$ : evidence from clinical trials and post-marketing surveillance. Dermatology 2007; 215 Suppl 1:27-44.
76. Chen SL, Yan J, Wang FS. Two topical calcineurin inhibitors for the treatment of atopic dermatitis in pediatric patients: a metaanalysis of randomized clinical trials. J Dermatolog Treat 2010;21: 144-56.

77. Rustin $\mathrm{MH}$. The safety of tacrolimus ointment for the treatment of atopic dermatitis: a review. Br J Dermatol 2007; 157: 861-73.

78. Pereira U, Boulais N, Lebonvallet N, Pennec JP, Dorange G, Misery L. Mechanisms of the sensory effects of tacrolimus on the skin. $\mathrm{Br} J$ Dermatol 2010; 163: 70-7.

79. Ständer S, Ständer $H$, Seeliger S, Luger TA, Steinhoff $M$. Topical pimecrolimus and tacrolimus transiently induce neuropeptide release and mast cell degranulation in murine skin. $\mathrm{Br} J$ Dermatol 2007; 156: 1020-6.

80. Ständer S, Siepmann D, Herrgott I, Sunderkötter C, Luger TA. Targeting the neurokinin receptor 1 with aprepitant: a novel antipruritic strategy. PloS One 2010; 5: e10968.

81. Billich A, Aschaver $H$, Aszodi A, Stuetz A. Percutaneous absorption of drugs used in atopic eczema: pimecrolimus permeates less through skin than corticosteroids and tacrolimus. Int J Pharm 2004; 269: 29-35.

82. Van Leent EJ, Ebelin ME, Burtin P, Dorobek B, Spuls PI, Bos JD. Low systemic exposure after repeated topical application of Pimecrolimus (Elidel), SD Z ASM 981 in patients with atopic dermatitis. Dermatology 2002; 204: 63-8.

83. Allen BR, Lakhanpaul $M$, Morris $A$, et al. Systemic exposure, tolerability, and efficacy of pimecrolimus cream $1 \%$ in atopic dermatitis patients. Arch Dis Child 2003; 88: 969-73.

84. Lakhanpaul $M$, Davies $T$, Allen BR, Schneider D. Low systemic exposure in infants with atopic dermatitis in a 1-year pharmacokinetic study with pimecrolimus cream 1\%*. Exp Dermatol 2006; 15: 138-41.

85. Draelos Z, Nayak A, Pariser D, et al. Pharmacokinetics of topical calcineurin inhibitors in adult atopic dermatitis: a randomized, investigator-blind comparison. J Am Acad Dermatol 2005; 53: 602-9.

86. Thaci D, Salgo R. Malignancy concerns of topical calcineurin inhibitors for atopic dermatitis: facts and controversies. Clin Dermatol 2010; 28: 52-6

87. Arellano FM, Wentworth CE, Arana A, Fernandez C, Paul CF. Risk of lymphoma following exposure to calcineurin inhibitors and topical steroids in patients with atopic dermatitis. J Invest Dermatol 2007; 127: 808-16.

88. Carr WW. Topical Calcineurin Inhibitors for Atopic Dermatitis: Review and Treatment Recommendations. Paediatr Drugs 2013.

89. Berger TG, Duvic M, Van Voorhees AS, VanBeek M, Frieden IJ. The use of topical calcineurin inhibitors in dermatology: safety concerns. Report of the American Academy of Dermatology Association Task Force. J Am Acad Dermatol 2006; 54: 818-23.

90. Tennis P, Gelfand JM, Rothman KJ. Evaluation of cancer risk related to atopic dermatitis and use of topical calcineurin inhibitors. BrJ Dermatol 201 1; 165: 465-73.

91. Spergel JM, Paller AS. Atopic dermatitis and the atopic march. $J$ Allergy Clin Immunol 2003; 1 12: S1 18-27.

92. Bonifazi E, Garofalo L, Pisani V, Meneghini CL. Role of some infectious agents in atopic dermatitis. Acta Derm Venereol Suppl (Stockh) 1985; 114:98-100.

93. Giannetti A. Viral skin diseases in atopic dermatitis. In: Happle R, Grosshans E, editors. Pediatric dermatology. Berlin: Springer-Verlag, 1987: 110-3.

94. David TJ, Longson M. Herpes simplex infections in atopic eczema. Arch Dis Child 1985; 60: 338-43.

95. Seize $M B$, lanhez $M$, Cestari SC. A study of the correlation between molluscum contagiosum and atopic dermatitis in children. An Bras Dermatol 201 1; 86: 663-8. 